\title{
Construções idiomáticas com o verbo pagar no português brasileiro
}

\section{Idiomatic constructions with the verb pagar (to pay) in Brazilian Portuguese}

\author{
Jussara ABRAÇADO* \\ Eduardo Santana MOREIRA**
}

RESUMO: Neste artigo, com o suporte teórico da Linguística Cognitiva, mais especificamente, da Gramática Cognitiva, são analisadas ocorrências de construções idiomáticas com o verbo pagar levantadas em diferentes sites da internet com o auxílio da ferramenta de busca Google. Como resultados (i) demonstra-se que tais construções idiomáticas decorrem da construção esquemática SN TRANSFERIR SN PARA SN que, por sua vez, provém de construção ainda mais esquemática SN V SN SPREP; (ii) são explicitadas peculiaridades no uso das construções levantadas, relações que mantêm entre si, no que diz respeito ao encadeamento de significados e a contextos de usos relacionados ao surgimento das construções analisadas; (iii) é formulada a rede construcional do verbo pagar contendo as construções em questão.

\begin{abstract}
In this paper, with the theoretical support of Cognitive Linguistics, more specifically, Cognitive Grammar, we analyze occurrences, in Brazilian Portuguese, of idiomatic constructions with the verb pagar (to pay) collected on different internet sites with the help of the Google search tool. As a result, (i) we demonstrate that such idiomatic constructions result from the schematic construction NP TRANSFER NP TO NP which, in turn, comes from an even more schematic construction NP V NP SPREP; (ii) we explain the peculiarities in the use of these constructions as well as the relationships they maintain among themselves with regard to the chain of meanings and contexts related to the emergence of these constructions; (iii) we formulated the constructional network of the verb pagar (to pay) containing referred constructions.
\end{abstract}

\footnotetext{
* Professora Titular de linguística da Universidade Federal Fluminense. ORCID: https://orcid.org/00000002-1050-9500. mjabracadoalmeida@id.uff.br.

** Mestre pela Universidade Federal Fluminense. ORCID: https://orcid.org/0000-0002-9840-5625. eduardo.santana3@yahoo.com.br.
} 


\begin{tabular}{ll}
\hline PALAVRAS-CHAVE: $\quad$ Construções & KEYWORDS: Idiomatic constructions. \\
idiomáticas. Verbo pagar. Gramática & Verb pagar (to pay). Cognitive Grammar. \\
Cognitiva. Português brasileiro. & Brazilian Portuguese. \\
\hline
\end{tabular}

\section{Introdução: etimologia e usos do verbo pagar}

Os primórdios do verbo pagar remontam o sânscrito paçus (ovelha/carneiro), pecus em latim, com origem nas transações comerciais que eram praticadas, tomandose por base o carneiro, a ovelha e, posteriormente, o gado, que serviam de moeda de retribuição. Pacãre no latim vulgar, seguindo os temas pax e pacis, licenciou os sentidos de apaziguar, acalmar e satisfazer ajustados à situação de dívida: pagando-se o que se deve, fica-se em paz com a consciência e com os credores (BUENO, 1968).

Para Sacconi (2010), a acepção desse verbo, em português, relaciona-se à ideia de dar dinheiro em troca de mercadorias, de liquidar, de retribuir, de recompensar e de gastar. Sendo assim, os falantes podem utilizá-lo com o sentido de transferir um valor monetário, como no seguinte exemploํ:

(1) “Giuliani diz que Trump pagou por silêncio de atriz pornô. (https://www.dw.com/pt-br/giuliani-diz-que-trump-pagou-porsil\%C3\%AAncio-de-atriz-porn\%C3\%B4/a-43632519)

Sacconi (2010) lista ainda algumas expressões populares, entre as quais, estão pagar sem bufar, pagar caro, pagar um alto preço, pagar com a vida, que se vinculam à ideia de se arcar severamente com as consequências de um comportamento.

Bueno (1968), por sua vez, referindo-se às expressões pagar o pato e pagar promessa, explica que a primeira carreia o sentido de se levar a culpa de um malfeito

\footnotetext{
${ }^{1}$ Todos os exemplos apresentados neste trabalho foram coletados em sites da internet, no período de janeiro de 2018 a janeiro de 2020, utilizando-se como ferramenta o buscador Google. Para propiciar o acesso ao texto completo, disponibilizamos os respectivos links juntamente com cada caso ilustrado.
} 
alheio, enquanto a segunda tem seu emprego relacionado ao cumprimento do prometido a Deus ou a santo(s).

Asseveram os autores referidos que o verbo pagar, quando usado no sentido mais básico, transmite um caráter valorativo de justiça, isto é, de quitação de pendências. Contudo, quando distanciado desse sentido, tende a apresentar um significado relacionado a sofrimento e aflição como, por exemplo, em pagar os pecados. Sacconi (2010) cita ainda outras duas expressões, também distanciadas do sentido básico do verbo pagar, muito utilizadas no português brasileiro (PB): pagar mico e pagar com a (ou na) mesma moeda, estando a primeira aliada à noção de se ver em uma situação embaraçosa ou vexatória, enquanto a segunda relaciona-se à ideia de se retribuir, do mesmo modo ou na mesma proporção, atitudes que, em geral, não são bem-vindas.

Além desses usos arrolados em estudos anteriores, encontramos outros como: Pagar geral, Pagar pra ver, Pagar a mão, Pagar o chão, Pagar barriguinha, Pagar de santo etc., que indicam haver uma rede construcional extensa ligada ao verbo pagar. No entanto, para se chegar à configuração dessa rede, faz-se necessário, antes, desvelar as relações existentes entre as diversas construções com pagar. Nosso propósito neste estudo é justamente esse: com base em levantamento que fizemos de construções idiomáticas com o verbo pagar no PB, explicitar características das construções levantadas e relações que mantêm entre si, em termos de encadeamento de significados e contextos de usos, que podem ter licenciado seu surgimento, chegando assim à rede construcional do verbo pagar, no que se refere a tais construções. Para tanto, vamos nos pautar no referencial teórico da Linguística Cognitiva e, mais especificamente, da Gramática Cognitiva (LANGACKER 1987, 1990, 1991 e 2005), sobre a qual falaremos a seguir. 


\title{
2 A Gramática Cognitiva e a noção de construção
}

Langacker, a partir de 1976, passou a desenvolver uma teoria linguística, a Gramática Cognitiva, que se afasta radicalmente de algumas suposições correntes na ocasião como, por exemplo, a de que a linguagem é um sistema autossuficiente, com autonomia para ser estudado isoladamente de preocupações cognitivas mais amplas, e a de que a gramática, especialmente a sintaxe, é um aspecto da estrutura linguística independente e distinto do léxico e da semântica (LANGACKER, 2006).

Para a Gramática Cognitiva, portanto, a linguagem não é independente nem descritível sem referência essencial ao processamento cognitivo; as estruturas gramaticais não constituem um sistema formal autônomo, diferentemente, são inerentemente simbólicas; e léxico, morfologia e sintaxe formam um contínuo de unidades simbólicas.

Sob esse viés, conforme nos explicam Silva e Batoréo (2010),

\begin{abstract}
A gramática é entendida como um sistema de estruturação conceptual, que envolve capacidades cognitivas gerais, como a percepção, a atenção, a categorização, a memória; os conhecimentos que temos sobre o mundo, integrando assim uma semântica enciclopédica; e mecanismos imaginativos, como a metáfora, a metonímia, a mesclagem conceptual, a evocação de entidades fictivas (SILVA; BATORÉO, 2010, p. 230).
\end{abstract}

Um dos princípios essenciais em Linguística Cognitiva é o de que o significado é conceptualização. Conceptualização, por sua vez, consiste num processo de apreensão, em termos cognitivos, de uma dada entidade ou situação (objeto de conceptualização) por um conceptualizador (sujeito de conceptualização). Langacker designa Construals esses modos alternativos de conceptualizar determinada situação. Vejamos o que dizem a respeito Silva e Batoréo (2010, p. 233):

Em Linguística Cognitiva, costuma designar-se pela expressão perspectivação conceptual (tradução que propomos para o termo 
inglês "construal") o modo e os modos alternativos de conceptualizar determinada situação. Esses modos alternativos envolvem operações de perspectivação conceptual e estas operações correspondem a capacidades cognitivas gerais.

Esta capacidade de perspectivação conceptual tem sido explorada sobretudo por Langacker $(1987,1991,1999)$ e por Talmy $(2000)$ e ambos a têm evidenciado como a função central da gramática.

As ideias centrais da Gramática Cognitiva, de acordo com Langacker (2005), são as seguintes:

Léxico, morfologia e sintaxe formam um continuum, dividido apenas arbitrariamente em "componentes" discretos. Tudo nesse continuum é totalmente descritível como assembleias de estruturas simbólicas. Uma estrutura simbólica é definida especificamente como o pareamento entre uma estrutura semântica e uma estrutura fonológica (seus polos semântico e fonológico). Isso tem certas consequências. Primeiro, a gramática não é distinta da semântica, mas a incorpora como um polo. Segundo, os elementos da descrição gramatical não são especiais, primitivos irredutíveis, mas reduzem-se a pares de significado-forma. Finalmente, todo constructo gramatical válido deve ser significativo (LANGACKER, 2005, p. 104).

Para Langacker (2005), existem três versões de gramática da construção, a Gramática Cognitiva, a Gramática da Construção e a Gramática Radical da Construção, que compartilham "uma lista substancial de ideias básicas". Vamos à lista apresentada por ele:

(i) Construções (em vez de "regras") são os principais objetos de descrição. (ii) As estruturas não são derivacionais ("monostratais"). (iii) O léxico e a gramática não são componentes distintos, mas formam um continuum de construções. (iv) Construções são pares de forma e significado ("assembleias de estruturas simbólicas"). (v) A estrutura da informação é reconhecida como uma faceta dos significados construtivos. (vi) As construções estão ligadas em redes de herança ("categorização"). (vii) As regularidades (regras, padrões) assumem a forma de construções esquemáticas em relação às expressões que 
estanciam. (viii) À parte o grau de especificidade/esquematicidade, as expressões e os padrões que elas instanciam têm o mesmo caráter básico. (ix) O conhecimento linguístico compreende grande número de construções, uma proporção grande das quais é "idiossincrática" em relação a padrões gramaticais produtivos "normais". (x) Uma estrutura que acomoda construções "idiossincráticas" acomodará facilmente padrões "regulares" como um caso especial (mas não o contrário). (xi) A boa formação é uma questão de satisfação simultânea de restrições. (xii) A composição é efetuada por "unificação" (integração) (LANGACKER, 2005, p. 102).

Mas há alguns aspectos em que as três versões apresentam pontos de vista diferentes. As três concordam, por exemplo, que 'construções' substituem o léxico e a gramática e que se reduzem a pares de significado e forma. No entanto, tal semelhança, assinala Langacker, esconde um ponto fundamental de "não concordância":

Este ponto de não concordância diz respeito ao que se entende por forma. Na Gramática Cognitiva, como está claramente explicitado em todas as formulações publicadas, a forma em um pareamento significado-forma é especificamente uma estrutura fonológica. É claro que eu generalizaria para incluir outras mídias simbolizadoras, notadamente o gesto e a escrita (Langacker 1987a: 81, 2001). Mas, crucialmente, isso não inclui o que pode ser chamado de forma gramatical. Em ambas, Gramática da Construção e Gramática Radical da Construção, a parte da forma de um pareamento significado-forma inclui a forma gramatical. Assim, Goldberg (1995:51) fala de "um pareamento entre um nível semântico e um nível sintático de funções gramaticais". Mais explicitamente, Croft (2001:62) diz que uma construção é simbólica em virtude de ser "um pareamento de uma estrutura morfossintática com uma estrutura semântica" (LANGACKER, 2005, p. 104).

Langacker não considera trivial a questão que envolve o pareamento forma e significado, uma vez que envolve a natureza da gramática e sua relação com o significado. Para a Gramática Cognitiva, ressalta o autor, a gramática é de natureza simbólica. "Nesta visão, a gramática (ou a forma gramatical) não simboliza a estrutura semântica, mas a incorpora, como um de seus dois polos", ou seja, "a gramática se 
reduz a algo mais fundamental e, portanto, não aparece em tais diagramas como uma caixa separada" (LANGACKER 2005, p. 105).

Assim sendo, nas representações da Gramática Cognitiva, os símbolos referentes a verbo (V), a sintagmas nominais (SN) etc. são apenas notações, uma vez que as noções de verbo, nome, sujeito, objeto etc. são semanticamente definíveis e inerentes às construções. Um substantivo, por exemplo, instancia o esquema [[COISA] / [X]], e um verbo, o esquema [[PROCESSO] / [Y]]. Cumpre destacar que [COISA] e [PROCESSO] são noções semânticas abstratas e que [X] e [Y] são estruturas fonológicas altamente esquemáticas, que especificam pouco mais do que a presença de algum conteúdo fonológico (LANGACKER, 2006). As noções de sujeito e objeto, por sua vez, são abarcadas pelas de Trajector e Marco, postuladas por Langacker e inspiradas em verbos prototípicos de ação, em que o Trajector é geralmente o motor inicial ou primário, enquanto o Marco pode se referir à meta, ao alvo, ao paciente ou a outra entidade que mantenha relação com o Trajector. A assimetria Trajector/Marco, portanto, subjaz à distinção sujeito/objeto, embora Trajector e Marco tenham aplicação consideravelmente mais ampla. Langacker (2005) atribui essa assimetria à organização figura/fundo: a predicação relacional eleva um de seus participantes, o Trajector, ao status de figura, ao passo que outros participantes são referidos como fundo. Em tal assimetria, o Marco é o destaque focal secundário.

Considerando que o conhecimento linguístico de um falante é processual, em vez de declarativo, e que a gramática internalizada representa esse conhecimento, Langacker diz que a gramática é um "inventário estruturado de UNIDADES linguísticas convencionais" (LANGACKER, 2006, p. 44; destaque do autor). O autor chama ainda a atenção para o termo 'unidade', que é empregado em um sentido técnico, para indicar uma estrutura que pode ser ativada como um todo préempacotado, sem que o falante atente para as especificidades de sua composição interna. A unidade, então, provém de uma rotina cognitiva, havendo um inventário 
de unidades convencionais estruturado, "no sentido de que algumas unidades funcionam como componentes de outras (ou seja, constituem sub-rotinas)" (LANGACKER, 2006, p. 44).

A Gramática Cognitiva, segundo Langacker (2005), concorda com a Gramática da Construção ao conceber que as redes de assembleias simbólicas (hierarquias de construções) englobam léxico e gramática, sem distinção essencial entre eles. No entanto, Langacker assinala uma diferença substancial entre as duas abordagens, no que diz respeito aos motivos para o reconhecimento da existência de uma construção e seu estatuto como uma unidade linguística convencional:

Na Gramática da Construção, uma construção é reconhecida apenas se algum de seus aspectos for imprevisível a partir de suas partes componentes, ou de outras construções estabelecidas independentemente (Goldberg 1995: 4). Não existe tal requisito na gramática cognitiva, em que uma assembleia é aceita como parte da "gramática" na medida em que é psicologicamente enraizada e convencional na comunidade da fala (LANGACKER, 2005, p. 140).

O autor ilustra essa diferença, tomando como exemplo a sentença I love you, que é apreendida como unidade convencional em língua inglesa, mas não exibe nenhuma idiossincrasia óbvia:

Todo falante do inglês conhece [I love you] como uma expressão fixa, familiar. Se eu a usar, não preciso construí-la ativamente do zero, evocando itens lexicais componentes e combinando-os de acordo com os esquemas construtivos apropriados - ela vem como uma unidade pré-empacotada. Por outro lado, é totalmente analisável e instancia os esquemas em questão. Além disso, carece de quaisquer idiossincrasias evidentes que impediriam sua construção novamente de acordo com os esquemas. Portanto, não é uma construção conforme definida na Gramática da Construção. No entanto, é uma unidade linguística convencional, conforme definida na Gramática Cognitiva (LANGACKER, 2005, p. 140-1). 
No que diz respeito a redes construcionais, Langacker (2005) esclarece que as assembleias simbólicas estão em redes de relacionamentos de categorização.

Cumpre então destacar que, para a Gramática Cognitiva e, por extensão, também para nós, o significado de uma construção não precisa ser parcialmente ou completamente independente das palavras que a compõem. São reconhecidas como construção todas as unidades psicologicamente enraizadas e convencionais numa comunidade da fala (LANGACKER, 2005).

Vejamos uma configuração esquemática apresentada por Langacker (2005) para construções bitransitivas em inglês (com elipse no lado esquerdo):

Figura 1 - configuração esquemática de construções bitransitivas em inglês.

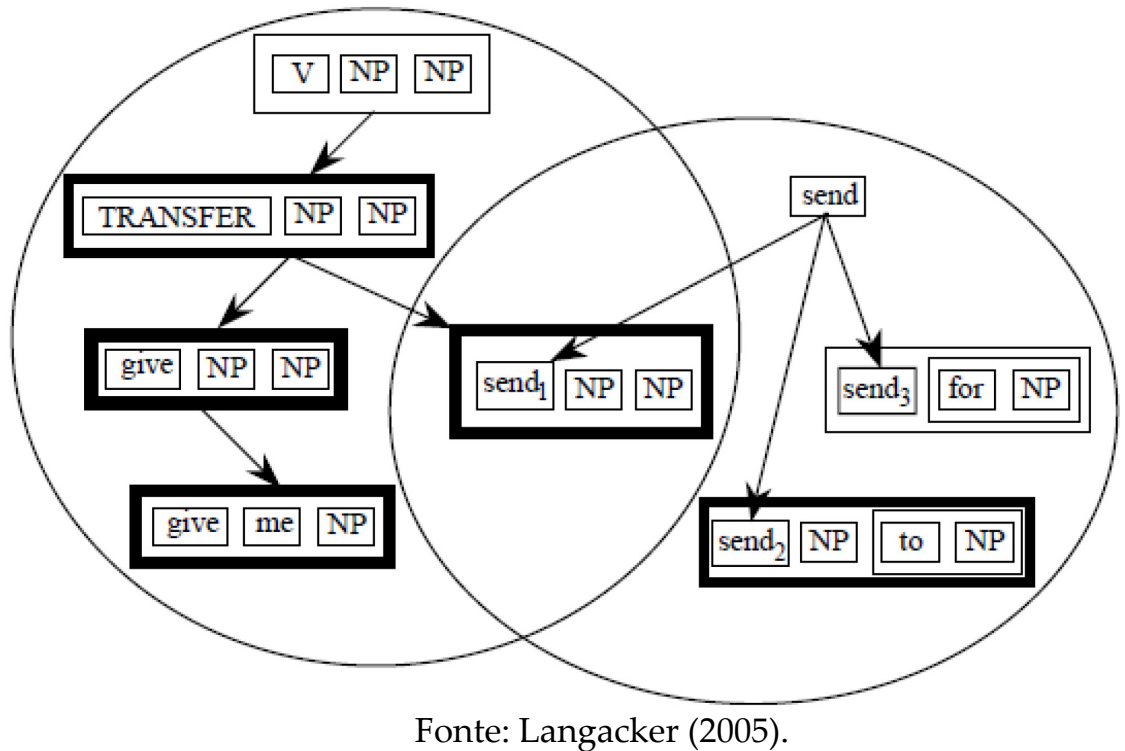

Observemos, nessa configuração, que alguns sentidos são 'esquemáticos' em relação a outros, como indicam as setas, e que o nível mais esquemático apresentado da construção bitransitiva é V NP NP (V SN SN, em português). Há níveis ainda mais esquemáticos, como os que mencionamos aqui, referentes a substantivos ([[COISA] / $[\mathrm{X}]])$ e a verbos ([[PROCESSO] / [Y]]), e outros referentes a unidades maiores, como sintagmas e cláusulas. Um SN, por exemplo, é caracterizado por Langacker como um substantivo [COISA] ancorado num evento de fala. O mesmo vale para uma cláusula 
finita. Isto porque, segundo o autor, um substantivo simples, como 'cachorro', e uma forma verbal simples, como 'saltar', servem apenas à função semântica mínima de fornecer uma especificação de tipo inicial, que é submetida a refinamentos, ajustes e quantificação em níveis mais altos de organização. Diferentemente, um SN como “o cachorro" implica que falante e ouvinte compartilham de informações que licenciam a utilização do artigo definido; implica também que falante e ouvinte têm chances de sucesso em estabelecer contato mental com a instância da coisa perfilada (LANGACKER, 2002). Do mesmo modo, a distinção entre 'saltar' e 'o cachorro saltou' está na ancoragem ao evento de fala, promovida pela desinência verbal de tempo².

Outro detalhe a ser notado na configuração apresentada são as bordas em traçado mais forte que correspondem a construções mais convencionais. É, contudo, necessário esclarecer que, para Langacker, a configuração exata de uma rede é menos importante do que reconhecer a inadequação de qualquer descrição reducionista do significado de uma unidade linguística. O conhecimento de um falante acerca do valor convencional de uma unidade linguística não pode, argumenta o autor, ser reduzido a uma única estrutura, tal como um protótipo ou um esquema de nível mais alto, uma vez que não há como se prever com precisão qual variedade de extensões e elaborações - entre todas concebíveis e linguisticamente plausíveis - alcançou, de fato, o status de unidade convencional. Ademais, as estruturas semânticas são caracterizadas em relação a "domínios cognitivos". Um domínio cognitivo pode ser qualquer tipo de conceptualização: a experiência perceptiva, um conceito, um complexo conceptual, um sistema de conhecimento elaborado etc. Certas conceptualizações pressupõem outras para sua caracterização, ou seja, pressupõem hierarquias de complexidade conceptual, em que as estruturas de um determinado nível emergem através de operações cognitivas performadas em estruturas de níveis

\footnotetext{
2 Ver Langacker (1991) para maiores informações a respeito
} 
mais baixos. Os domínios cognitivos exigidos por predicações linguísticas podem ocorrer em qualquer nível em tais hierarquias (LANGACKER 2002).

Considerando o exposto e, portanto, sem nos atermos ao nível de convencionalidade das construções, concluímos que o nível mais esquemático de uma construção com o verbo 'pagar' refere-se ao esquema construcional de sentenças bitransitivas no português (X TRANSFERE $\mathbf{Y}$ PARA $\mathbf{Z}$ ), havendo, contudo, o envolvimento, nem sempre explicitado, de uma mercadoria/dívida pela qual se paga (X TRANSFERE $\mathbf{Y}$ PARA $\mathbf{Z}$ (por K)), conforme exemplo de caráter ilustrativo a seguir:

(2) TV Brasil pagou $\mathrm{R} \$ 3,2$ milhões a Record por novela https://oglobo.globo.com/epoca/guilherme-amado/tv-brasil-pagou-32milhoes-record-por-novela-24952255

Tomando como base a Figura 1, formulamos então uma configuração básica das construções idiomáticas com o verbo pagar no PB (com elipse também à esquerda) que apresentamos em seguida.

Figura 2 - configuração esquemática do verbo pagar no PB.

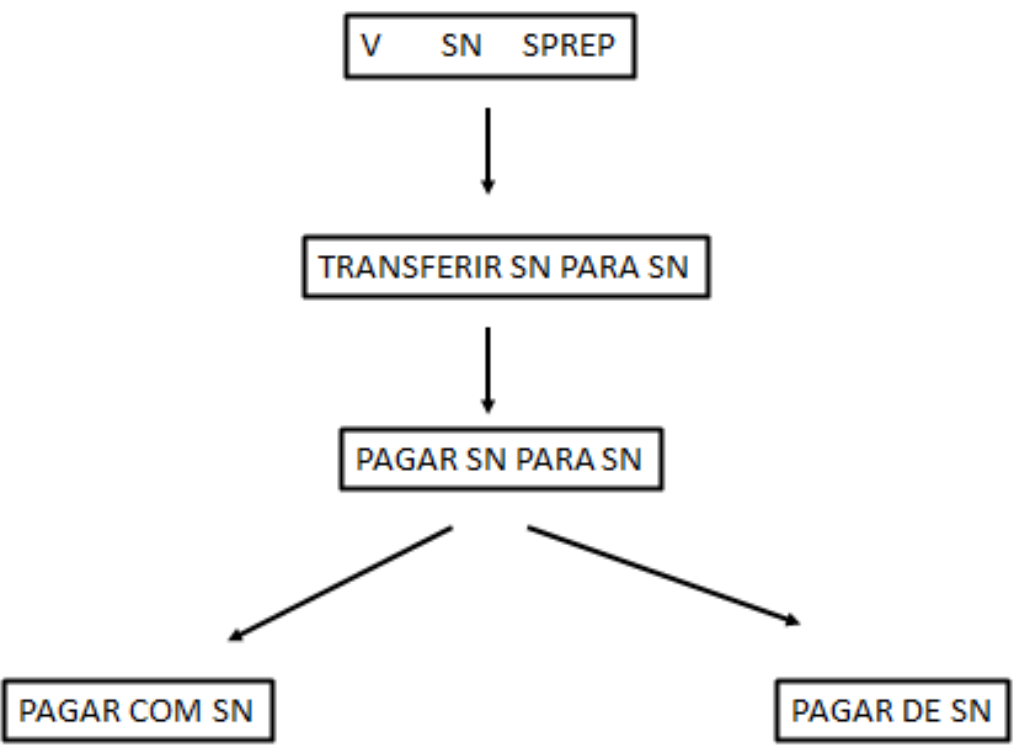


Tal configuração será retomada mais adiante e ligeiramente modificada para acomodar as construções idiomáticas com o verbo pagar que encontramos em nosso levantamento.

\section{Construções idiomáticas: frequência e rotinização}

Neste estudo, não vamos nos ocupar com a construção bitransitiva, propriamente dita, visto que nosso interesse está em construções outras que dela decorrem, nomeadamente, nas construções idiomáticas com o verbo pagar.

As construções idiomáticas ganharam espaço em pesquisas no âmbito da Linguística Cognitiva, uma vez que esta vertente teórica rejeita a noção de autonomia da sintaxe (em que não há lugar para as construções idiomáticas) e toma a diversidade linguística e cultural como recursos compartilhados cujos traços refletem aspectos universais do corpo humano, da mente e da experiência. Os estudos linguísticos de cunho cognitivista consideram a influência de fatores sociais, interacionais e culturais, já que, sob tal perspectiva, as mentes individuais não são entidades autônomas, e a linguagem e a cognição são reflexos decorrentes da interação social mediada pela cultura. Assim sendo, postula-se que o conhecimento da língua emerge do uso e, portanto, aspectos pragmáticos envolvidos na produção linguística constituem expediente para o encadeamento do pensamento, da palavra e de construções.

Muitos estudos foram realizados com base nessa percepção e observa-se um crescente interesse em se estudar construções idiomáticas (NUNBERG; SAG; WASOW, 1994; FILLMORE et al., 1988; CROFT; CRUSE, 2004), visto que, por um longo período de tempo, tais construções foram rejeitadas por serem consideradas exceções no domínio da sintaxe.

Com base em tais estudos, sabemos que: (i) o surgimento de novos usos linguísticos ocorre em situações de interação, uma vez que cada situação de interação verbal cria condições para que novos usos ocorram; (ii) mesmo que o falante opte por 
construções mais antigas, cada vez que uma dada construção é evocada, ela se torna minimamente diferente do que era.

Além do mais, tanto construções antigas quanto as emergentes coexistem em comunidades de fala, podendo acontecer, com o passar do tempo, que uma delas adquira maior frequência de uso e então se torne convencional. Um dos critérios considerados para que uma expressão idiomática se convencionalize é justamente a rotinização. A rotinização decorre da alta frequência de uso o que, por sua vez, implica menor esforço cognitivo.

Givón (1995) já chamava atenção para a relação entre complexidade cognitiva e frequência ao explicar a noção de marcação e alegar que, quanto maior a complexidade cognitiva de um termo ou expressão, menor será sua frequência de uso e maior será sua complexidade estrutural. Em direção oposta, quanto menor a complexidade cognitiva do termo ou expressão, maior será sua frequência de uso e menor será sua complexidade estrutural.

Outro aspecto importante a ser destacado em relação às construções idiomáticas diz respeito ao grau de opacidade: há construções idiomáticas mais transparentes, com significados presumíveis a partir do significado da combinação de seus componentes, como em "pagar caro", enquanto há outras mais opacas cujo significado é holístico e não composicional, como em "pagar mico". No tocante às construções idiomáticas com o verbo pagar, conforme demonstraremos, verifica-se um contínuo entre transparência e opacidade.

\section{Os dados}

Os dados desta pesquisa foram coletados em sites da internet, no período de janeiro de 2018 a janeiro de 2020, utilizando-se como ferramenta o buscador Google. Procedimentos de coleta e análise de dados dessa natureza, que se convencionou chamar de 'web como corpus', têm ganhado muitos adeptos. Segundo Gatto (2014, p. 
36), o uso da web como corpus surge como ferramenta inovadora e abre uma miríade de novas vias de pesquisas para comparação de diferentes tipos de textos para tratamentos sociolinguísticos, ensino de línguas, lexicografia, entre outros.

Pesquisadores diversos concordam que o uso desse recurso metodológico permite o contato com uma coleção de textos autênticos produzidos em circunstâncias espontâneas cujo objetivo não é o de exibir sua competência linguística, mas sim, o de alcançar um propósito comunicativo legítimo através da linguagem. Entre tais pesquisadores, está Gatto (2014) que defende esse ponto de vista por compreender que não haveria razão para se recorrer à web, como um objeto de estudo linguístico, se não fosse pelo fato de ser composta de textos autênticos resultantes de eventos comunicativos genuínos, produzidos por pessoas que negociam interesses comuns. É interessante se notar que os dados disponíveis para a análise resultam de um arcabouço rico, que tem como escopo diferentes gêneros textuais: jornalísticos, memes, blogs, posts em redes sociais, entre outros.

Para termos acesso a esse rico arcabouço e ainda para ampliarmos, em termos de ambientes virtuais, o escopo da pesquisa, na coleta de dados, foi utilizada a ferramenta de busca Google sem qualquer filtro. As buscas realizaram-se através de palavras-chave constituídas de flexões de tempo, modo e pessoa do verbo pagar ('pagar', 'paguei', 'pagou', pagará', 'pagaram', 'pagariam' etc.), o que nos permitiu montar um corpo de dados constituído de diferentes gêneros textuais e capturar construções com o verbo pagar restritas a determinados contextos e comunidades.

Embora bastante interessante, essa característica do nosso corpus não receberá aqui atenção especial. Neste estudo, vamos nos ater ao levantamento feito das construções com o verbo pagar, buscando demonstrar as especificidades de tais construções, as relações que mantêm entre si, ou melhor, o encadeamento que se observa entre as construções, relativamente a extensão de significado e de contextos de uso, e a posição que ocupam na rede construcional do verbo pagar. Para tanto, não 
podemos desconsiderar as circunstâncias relacionadas ao ato de pagar, que podem servir de contextos-gatilho para novos usos e emergência de novas construções. Temos, por conseguinte, que levar em conta que pagar remete tanto a transações comerciais, em que o pagamento se dá em troca de um produto, quanto a transações referentes a empréstimos e contração de dívidas de uma forma geral. Em outras palavras, temos de considerar a condição de submissão, de obrigação de um devedor, em relação ao credor, em termos jurídicos e sociais (o que, em alguns casos, pode resultar em situações de constrangimento e vexação) e, ainda, outros contextos e aspectos variados que envolvam dívidas, transferências (de valor monetário ou não), formas de pagamento, o não pagamento da dívida, etc.

\section{Análise dos dados}

Começamos por esclarecer que nossa análise é essencialmente de natureza qualitativa. Assim sendo, embora apresentemos, na tabela que se segue, totais de ocorrências e os respectivos percentuais referentes às construções levantadas, não realizamos análise quantitativa de natureza estatística. Tais percentuais, portanto, servem apenas para que tenhamos uma ideia da frequência de uso de uma dada construção, relativamente às demais, no período em que se deu a coleta. Dito isso, apresentamos, no Quadro 1, as construções com o verbo pagar levantadas na web. A disposição das construções no referido quadro diz respeito ao seu grau crescente de opacidade, conforme explicaremos ao apresentarmos exemplos das referidas construções. 
Tabela 1 - Construções idiomáticas com o verbo pagar.

\begin{tabular}{|c|c|c|c|c|c|}
\hline CONSTRUÇŌES & OCORRËNCIAS & $\%$ & \multirow{2}{*}{$\begin{array}{c}\text { Pagar com a mesma moeda/Pagar na } \\
\text { mesma moeda; }\end{array}$} & \multirow[t]{2}{*}{17} & \multirow[b]{2}{*}{$3 \%$} \\
\hline Pagar a mão & \begin{tabular}{|l|}
5 \\
\end{tabular} & $1 \%$ & & & \\
\hline Pagar o chão & 3 & $1 \%$ & Pagar esporro & 14 & $2 \%$ \\
\hline Pagar sem bufar & 9 & $2 \%$ & Pagar geral & 22 & $4 \%$ \\
\hline Pagar pra ver & 9 & $2 \%$ & Pagar opato & 61 & $11 \%$ \\
\hline Pagar promessa & 80 & $14 \%$ & Pagar pau & 10 & $2 \%$ \\
\hline Pagar pecado & 35 & $6 \%$ & Pagar mico & 84 & $15 \%$ \\
\hline Pagar a lingua & 24 & $4 \%$ & Pagar boquete / Pagar chupeta & 37 & $6 \%$ \\
\hline Pagar alto preço/Pagar preço alto & 27 & $5 \%$ & $\begin{array}{c}\text { Pagar calcinha/Pagar cofrinho/ Pagar } \\
\text { barriguinha/ etc. }\end{array}$ & 85 & $15 \%$ \\
\hline Pagar caro & 14 & $2 \%$ & Pagar de santo; pagar de louco; pagar & 26 & \\
\hline Pagar com juros & 3 & $1 \%$ & de rica etc. & & $5 \%$ \\
\hline Pagar com a vida & 8 & $1 \%$ & TOTAL & 573 & 100 \\
\hline
\end{tabular}

Como se pode constatar no quadro 1, há construções que ocorrem com mais frequência, enquanto há outras com percentuais de ocorrências baixíssimos. Estas, conforme detalharemos mais adiante, são em sua maioria construções que ocorrem em contextos muito específicos. O quadro 1 também nos mostra que o verbo pagar ocorre em construções diversas, com diferentes usos e com número variável de slots a serem preenchidos. Vejamos exemplos de cada uma dessas construções e em que circunstâncias são empregadas. Comecemos por aquelas em que o sentido de transferência de um valor monetário é preservado. A partir de então, conforme a disposição das construções no quadro 1, paulatinamente, vamos na direção da análise de construções mais opacas, com usos e significados mais distantes da bitransitiva esquemática em português.

(3) Pagar o chão:

(...) Aí começou a imperar nesse médium a ambição pelo ganho fácil, quando começa a exceder na 'Lei de Salva' (dentro da magia), dando a desculpa que necessita do dinheiro para o seu anjo da guarda, para o cambono, ou para 'pagar o chão'.

http://temploumbandacaboclopenabranca.blogspot.com/2013/06/fracassodo-medium.html

Pagar o chão é uma construção de uso próprio da comunidade espírita, mais especificamente da Umbanda e do Candomblé, e refere-se a um valor pago ao dirigente do terreiro. 
(4) Pagar a mão:

(...) a grande maioria... senão todos os rituais devem ser pagos. Isso pelo menos foi o que me disseram... deve-se pagar a mão, o chão, os materiais, etc...

https://ocandomble.com/2010/06/15/magia-para-venda/

Assim como a construção anterior, Pagar a mão também é de uso próprio da comunidade espírita da Umbanda e do Candomblé e refere-se a um valor pago pelos serviços religiosos.

(5) Pagar sem bufar:

O tema é velho: de onde tirar dinheiro, ou como fazer para pagar um direito reconhecido pela Justiça que, cega, surda e muda, mandou o governo pagar sem bufar?

https:/www.tribunapr.com.br/noticias/a-galinha-dos-ovos-de-ouro/

A construção Pagar sem bufar, conforme ilustrado em (5), refere-se a um valor monetário cobrado e a ser pago sem reclamação ou protesto.

(6) Pagar para ver:

No fim das contas eu já sabia o final dessa história, mas a gente tem essa mania de pagar pra ver na esperança de descobrir que estava enganado. https://www.tumblr.com/search/pagar\%20pra\%20ver

Pagar para ver, que tem seu uso convencionalizado em jogos que envolvem apostas em dinheiro, como o pôquer, fora desse contexto, também é empregada no sentido de apostar, mas não um valor monetário propriamente dito. Costuma ser utilizada em situações em que se decide tomar uma atitude ou firmar uma posição, correndo-se o risco de cometer um erro. 
(7) Pagar promessa:

Pagando promessa, fiel percorre $280 \mathrm{Km}$ a pé de Teresina a Oeiras

https://maisoeiras.com.br/noticias/pagando-promessa-fiel-percorre-280-

km-a-pe-de-teresina-a-oeiras/

A construção Pagar promessa, de base religiosa, é comumente utilizada em referência ao cumprimento do que foi prometido a Deus ou a santos, em geral católicos, em troca da realização de um pedido feito. Nesta construção, o pagamento também não está necessariamente atrelado a um valor monetário, mas a algum tipo de sacrifício ou penitência. Entretanto, pagar promessa costuma ser equiparada a pagar uma dívida. Há inclusive um ditado popular, ou seja, uma outra construção idiomática, que afirma que 'promessa é dívida'. O pagamento desse tipo de dívida, contudo, costuma se dar por meio de algum tipo de expiação.

(8) Pagar pecado:

Quem está pagando os pecados do governo petista são os contribuintes, diz colunista.

http://www.folhapolitica.org/2015/07/quem-esta-pagando-os-pecados-dogoverno.html

Da mesma base religiosa de Pagar promessa, a construção Pagar pecado tem seu uso relacionado a contextos em que o indivíduo se vê em um estado de expiação, passando por algum momento difícil que acredita ser decorrente de erros (ou pecados) cometidos. Nesta construção, fica bastante evidente o uso de pagar com o sentido de sofrimento compensatório de culpa também presente nas próximas sete construções.

(9) Pagar a língua:

Maternidade é pagar a língua

Vou contar uma coisa para vcs, antes de ser mãe eu tinha o péssimo hábito de julgar outras mães.

Agora olhando aquela Keila, vejo que mtas coisas que eu recriminava eu já fiz.

https://keilamota.wordpress.com/2019/06/24/maternidade-e-pagar-a-lingua/ 
Pagar a língua é uma construção idiomática empregada em contextos em que alguém age de modo que, anteriormente, não aceitava e costumava criticar quando observado em atitudes alheias.

(10) Pagar alto preço/Pagar preço alto:

Vai pagar um preço alto', diz Bolsonaro sobre militar com cocaína.

https://renovamidia.com.br/vai-pagar-um-preco-alto-diz-bolsonaro-sobremilitar-com-cocaina/

A construção idiomática Pagar alto preço/Pagar preço alto perfila uma faceta do verbo pagar - presente no frame de transação comercial ${ }^{3}$, do qual o verbo pagar faz parte - que não está prevista na configuração esquemática da construção bitransitiva. Tal faceta diz respeito ao preço e, portanto, envolve julgamento de valoração em relação ao que é pago (é caro, barato, justo, etc.). Tal construção é muito utilizada em referência às consequências de um comportamento, sendo comum o seu emprego para externar arrependimento por erros cometidos ou juízo de valor em relação ao comportamento alheio.

(11) Pagar caro

“Países do G-7 'tiram vantagem de nós' e Canadá 'pagará caro', diz Trump https://epocanegocios.globo.com/Mundo/noticia/2018/06/epoca-negociospaises-do-g-7-tiram-vantagem-de-nos-e-canada-pagara-caro-diztrump.html

A construção Pagar caro apresenta as mesmas características da construção anterior. Há, entretanto, um uso frequente desta, referindo-se ao comportamento do interlocutor ou de terceiros, implicando, além de juízo de valor, uma espécie de ameaça.

\footnotetext{
${ }^{3}$ Para mais informações ver Fillmore et. al. (1972); Moreira e Salomão (2012), entre outros.
} 
Existem outras construções com o verbo pagar que se referem ao valor a ser pago e que também envolvem juízo de valor, normalmente, voltado para o comportamento alheio, e que carreiam uma espécie de ameaça, como é o caso de Pagar com juros, Pagar com a vida e Pagar com a ou na mesma moeda.

(12) Pagar com juros

Na Carta de Dilma só faltou trechos de 'Apesar de Você', melhor recado a quem vai pagar com juros pelo impeachment sem crime.

https://www.brasil247.com/blog/na-carta-de-dilma-so-faltou-trechos-deapesar-de-voce-melhor-recado-a-quem-vai-pagar-com-juros-peloimpeachment-sem-crime

(13) Pagar com a vida

'Uns erram e outros pagam. Ela pagou com a vida', diz marido de aluna morta.

https://ultimosegundo.ig.com.br/brasil/sp/2012-08-24/uns-erram-e-outrospagam-ela-pagou-com-a-vida-diz-marido-de-aluna-morta.html

(14) Pagar na mesma moeda

Obama ordena expulsão de agentes russos, Putin recusa pagar na mesma moeda e confia na política de Trump.

http://novojornal.co.ao/internacional/interior/obama-ordena-expulsao-deagentes-russos-putin-recusa-pagar-na-mesma-moeda-e-confia-na-politicade-trump-36344.html

Observe-se, no entanto, que nessas construções há uma especificação quanto à forma de pagamento e que, enquanto Pagar com juros e Pagar com a vida referem-se ao alto preço a ser pago, Pagar com a ou na mesma moeda fazem alusão clara a um ato de vingança.

(15) Pagar esporro:

(...) O professor, obviamente, não quis nenhuma explicação. Declarando-me culpada de imediato - afinal fui pega em flagrante-, me pagou o maior esporro na frente da turma. 
https://medium.com/@simoneavellar/quando-um-telefone-quen\%C3\%A3o-era-meu-tocou-de-dentro-da-minha-mochila-durante-umaaula-dd0a22da66cc

Em (15) e nas construções seguintes, observa-se o comprometimento da composicionalidade das construções. Em (15), a transferência própria da bitransitiva realiza-se em termos verbais. Assim como metaforicamente se dá um conselho ou um sermão, também metaforicamente se "paga um esporro".

(16) Pagar geral

Jornalista flagra lateral do Palmeiras pagando geral após empate com direito a palavrões.

https://www.90min.com/pt-BR/posts/6435958-jornalista-flagra-lateral-dopalmeiras-pagando-geral-apos-empate-com-direito-a-palavroes

Na mesma linha de transferência metafórica está Pagar geral cujo significado holístico, que não pode ser depreendido a partir de seus componentes, é o de se repreender pessoas indiscriminadamente.

(17) Pagar o pato

'Seleção não pode pagar o pato por crise no Brasil', diz Daniel Alves https://www.metropoles.com/esportes/futebol/selecao-nao-pode-pagar-opato-por-crise-no-brasil-diz-daniel-alves/amp

Pagar o pato, assim como todas as construções que veremos em seguida, é caracterizada por total opacidade. Seu uso mais comum se dá em referência a situações em que alguém sofre punição ou algum tipo de pressão indevidamente.

(18) Pagar pau

Muitos aqui estão pagando pau pra torcida do A. Madrid, o time deles perdeu 3 mata mata contra o maior rival, já imaginou o Corinthians perdendo 3 vezes seguidas para o Palmares?

https://www.meutimao.com.br/forum-do-corinthians/bate-papo-datorcida/396978/pra-que-pagar-pau 
Pagar pau é empregada em diferentes regiões do Brasil com variação em termos de significado. Seu uso, no entanto, é mais frequente em contexto de bajulação, em que se mostra publicamente e ostensivamente admiração por alguém.

(19) Pagar mico

William Bonner 'paga mico' sem saber que estava ao vivo e entra nos TTs. https://extra.globo.com/noticias/viral/william-bonner-paga-mico-semsaber-que-estava-ao-vivo-entra-nos-tts-19863325.html

A construção Pagar mico refere-se a um ato embaraçoso ou vexatório, para os padrões sociais e/ou contextuais considerados, que ocorre involuntariamente ou não, e que, em geral, relaciona-se a situações cômicas.

(20) Pagar calcinha

Opa! Ana Hickmann gira e mostra truque esperto para não pagar calcinha. http://entretenimento.r7.com/carnaval-2013/fotos/opa-ana-hickmann-girae-mostra-truque-esperto-para-nao-pagar-calcinha-02022013\#!/foto/1

Na esteira das situações vexatórias, mas carreada de conotação sexual, esta construção se refere à exposição, involuntária ou não, de partes do corpo ou de peças íntimas de vestuário. Nesta construção, além do slot à esquerda, há também o slot à direita a ser preenchido. Assim, temos pagar peitinho, pagar cofrinho, pagar calcinha, pagar barriguinha, etc., como instanciações possíveis desta construção.

(21) Pagar boquete

Direta e sem papas na língua, Tessália disparou: "Pagar um boquete embaixo do edredom". A confissão, é claro, pegou todos de surpresa, já que ela havia dito que apenas beijou seu colega Michel.

https://rd1.com.br/ex-bbb-surpreende-e-confessa-que-fez-sexo-oral-noconfinamento/ 
De conotação nitidamente sexual e, portanto, de uso ligado a situações e contextos relacionados a práticas sexuais, as construções pagar boquete (e pagar chupeta) referem-se à prática de sexo oral.

(22) Pagar de

Jovem que fez vídeo com arma pagando de bandido, é encontrado morto com vários tiros.

https://portalcm7.com/noticias/policia/jovem-que-fez-video-com-armapagando-de-bandido-e-encontrado-morto-com-varios-tiros-veja-video/

Na construção Pagar de, utilizada no sentido de 'fingir-se de' ou 'fazer-se de', observa-se uma transferência, na avaliação do enunciador, de características ou atributos de uma dada entidade para outra. Em Pagar de há dois slots a serem preenchidos, o da esquerda e da direita.

Como se pode constatar, as construções idiomáticas com o verbo pagar em tela apresentam relações com diferentes de contextos-gatilho, ou seja, contextos propícios ao surgimento de novos usos e, por conseguinte, à emergência de novas construções. Sumariamos tais relações, já explanadas quando discorremos sobre cada construção, no quadro a seguir.

Quadro 2 -Relações entre contextos-gatilho e construções idiomáticas com verbo pagar

\begin{tabular}{|c|c|}
\hline CONTEXTOS-GATILHO & CONSTRUÇÕES IDIOMÁTICAS \\
\hline Transferência de valor monetário & Pagar a mão; pagar o chão; pagar sem bufar. \\
\hline Transferência em termos metafóricos & Pagar esporro; pagar geral; pagar de santo. \\
\hline $\begin{array}{l}\text { Pagamento por meio de atitudes, } \\
\text { sacrifícios ou expiação }\end{array}$ & $\begin{array}{l}\text { Pagar pra ver; pagar promessa; pagar } \\
\text { pecados. }\end{array}$ \\
\hline $\begin{array}{l}\text { Preço a ser pago como forma de } \\
\text { punição ou de revide }\end{array}$ & $\begin{array}{l}\text { Pagar a língua, pagar caro, pagar com juros, } \\
\text { pagar com a vida, pagar com a ou na mesma } \\
\text { moeda. }\end{array}$ \\
\hline $\begin{array}{l}\text { Situações que envolvem condição de } \\
\text { inferiorização, submissão ou } \\
\text { subalternação. }\end{array}$ & Pagar pau; pagar boquete; pagar chupeta. \\
\hline Exposição a situações vexatórias. & $\begin{array}{l}\text { Pagar o pato; pagar mico; } \\
\text { calcinha/pagar cofrinho etc. }\end{array}$ \\
\hline
\end{tabular}


Tendo discorrido sobre as construções levantadas, vamos retomar a configuração esquemática apresentada na Figura 2 e promover ligeiras modificações que permitam a acomodação das construções aqui abordadas.

Figura 3 - Rede construcional do verbo pagar no PB.

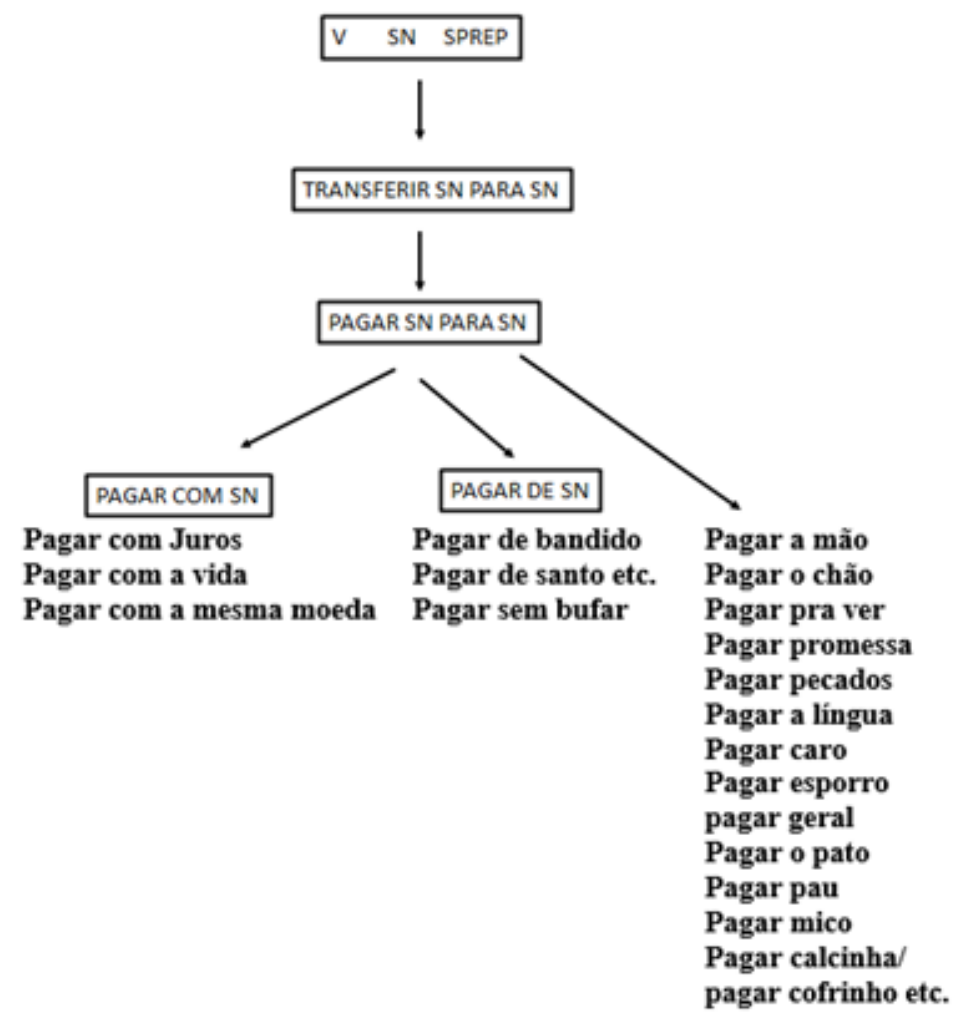

Cumpre ressaltar que a rede em questão não estabelece relações de natureza etimológica e encontra-se naturalmente em aberto e apta a novas incorporações, mesmo porque, vale relembrar, extensões de sentido e, por conseguinte, novas construções, podem emergir em qualquer ponto da rede, servindo de elo para novas extensões de significado e, então, para emergência de outras construções.

\section{Considerações finais}

Concluída a análise, vamos às conclusões. Como demonstramos em nossa explanação, as construções idiomáticas, assim como a construção bitransitiva com o 
verbo pagar (PAGAR SN PARA SN), decorrem da construção esquemática TRANSFERIR SN PARA SN que, por sua vez, provém de construção ainda mais esquemática V SN SPREP.

De acordo com o sentido etimológico e básico do verbo pagar, a construção, agora sem elipse à esquerda, SN PAGAR SN PARA SN refere-se à transferência de um dado valor monetário para pagamento de um produto ou quitação de uma dívida. Entretanto, considerando as circunstâncias que envolvem transações comerciais, contração de dívidas, a condição de um devedor (que se encontra, em termos jurídicos e sociais, em situação de submissão, de obrigação, em relação ao credor) e também as circunstâncias e contextos que envolvem dívidas em geral, transferências (de valor monetário ou não), quantias a serem pagas, formas de pagamento, o não pagamento da dívida etc., constatamos a existência de grande quantidade de contextos-gatilho implicados em seu surgimento. Como já mencionamos, novos usos linguísticos surgem em situações reais de interação, dado que, em cada situação de interação verbal, são geradas condições para a ocorrência de usos novos.

Para concluir, ressaltamos que os contextos-gatilho elencados no Quadro 2, aliados à configuração da rede construcional do verbo pagar na Figura 3, evidenciam que certas conceptualizações pressupõem outras para sua caracterização, isto é, pressupõem hierarquias de complexidade conceptual, em que estruturas de um determinado nível emergem por meio de operações cognitivas performadas em estruturas de níveis mais baixos (LANGACKER 2002).

\section{Referências Bibliográficas}

BUENO, F. da S. Grande dicionário etimológico-prosódico da língua portuguesa. São Paulo: Saraiva, 1968.

CROFT, W. Radical construction grammar: syntactic theory in typological perspective. Oxford: Oxford University Press, 2001. DOI https://doi.org/10.1093/acprof:oso/9780198299554.001.0001 
CROFT, W. Cognitive Linguistics. Cambridge: Cambridge University Press, 2004.

FILLMORE, C. J.; KAY, P.; O'CONNOR, M. C.. Regularity and idiomaticity in grammatical constructions: the case of let alone. Language, v. 64, n. 3, p. 501-538, 1988.

FILLMORE C. J.; ATKINS, B.T. Toward a Frame-Based Lexicon: Semantics of Risk e its Neighbours. In: LEHRER, A.; KITTAY, E. E. (ed.). Frames, Fields, and Contrasts: New Essays in Semantic and Lexical Organization. Hillsdale: Lawrence Erlbaum, 1992. p. 75-102. DOI https://doi.org/10.2307/414531

GATTO, M. The Web as Corpus: theory and practice. London: Bloomsbury, 2014. (Studies in Corpus and Discourse).

GIVÓN, T. Functionalism and grammar. Amsterdam/Philadelphia: John Benjamins, 1995.

GOLDBERG, A. Constructions. Chicago: University of Chicago Press, 1995.

LANGACKER, R. W. Foundations of Cognitive Grammar. Vol. I: Theoretical Prerequisites. Stanford, California: Stanford University Press, 1987.

LANGACKER, R. W. Concept, Image, and Symbol: the Cognitive Basis of Grammar. Berlin; New York: Mouton de Gruyter, 1990. (Cognitive Linguistics Research, 1).

LANGACKER, R. W. Foundations of Cognitive Grammar. Vol. II: Descriptive Application. Stanford, California: Stanford University Press, 1991.

LANGACKER, R. W. Grammar and Conceptualization. Berlin/New York: Mouton de Gruyter, 1999. DOI https://doi.org/10.1515/9783110800524

LANGACKER, R. W. Deixis and subjectivity. In: BRISARD, F. Grounding: The Epistemic Footing of Deixis and Reference. Berlin, New York: Mouton de Gruyter, 2002. p. 2-28. DOI https://doi.org/10.1515/9783110899801.1

LANGACKER, R. W. Construction Grammars: cognitive, radical, and less so. In: IBÁÑEZ, F. J. R. de M.; CERVEL, M. S. P. (ed.) Cognitive linguistics: internal dynamics and interdisciplinary interaction. Berlin/New York: Mouton de Gruyter, 2005. p. 101-59. 
LANGACKER, R. W. Introduction to Concept, Image, and Symbol. In: GEERAERTS, D. (ed.). Cognitive linguistics: basic readings. Berlin - New York: Mouton de Gruyter, 2006. p. 29-67.

MOREIRA, A.; SALOMÃO, M. M. M. Análise ontolológica aplicada ao desenvolvimento de Frames. Alfa: Revista de Linguística, 56(2), p. 491-521, 2012. DOI https://doi.org/10.1590/S1981-57942012000200007

NUNBERG, G.; SAG, I. A.; WASOW, T. Idioms. Language, v. 70, n. 3, p. 491-538, Sep. 1994. DOI https://doi.org/10.1353/lan.1994.0007

SACCONI, L. A. Grande dicionário Sacconi da língua portuguesa: comentado, crítico e enciclopédico. São Paulo: Nova Geração, 2010.

SILVA, L. A. da. Construções idiomáticas com o verbo pegar: uma abordagem sociocognitiva. Scripta, Belo Horizonte, v. 20, n. 40, p. 307-326, 2016. Acesso em: 3 maio 2016. DOI https://doi.org/10.5752/P.2358-3428.2016v20n40p307

SILVA, A. S. Perspectivação conceptual e Gramática. Revista Portuguesa de Humanidades - Estudos Linguísticos 12-1, p. 17-44, 2008.

SILVA, A. S.; BATORÉO, H. J. Gramática Cognitiva: estruturação conceptual, arquitectura e aplicações (2010). Disponível em: https://www.researchgate.net/publication/290790148 Gramatica Cognitiva estrutura cao conceptual arquitectura e aplicacoes. Acesso em: 15 jan. 2020.

TALMY, L. Toward a Cognitive Semantics. I: Concept Structuring Systems. II: Typology and Process in Concept Structuring. Cambridge, Mass.: The MIT Press, 2000. DOI https://doi.org/10.7551/mitpress/6848.001.0001

VERHAGEN, A. Construal and perspectivization. In: GEERAERTS, D.; CUYCKENS, H. (ed.). The Oxford Handbook of Cognitive Linguistics. Oxford: Oxford University Press, 2007. p. 48-81. 